\title{
IL1 Polymorphisms May Predispose Distal Interphalangeal Joints of the Hands to Effects of Mechanical Overload
}

The increasing impact of osteoarthritis (OA) on individuals, families, and society is considerable. For example, the prevalence of OA has increased in the United States to nearly 27 million, the third most prevalent condition causing work disability ${ }^{1}$. As expected, increasingly sophisticated studies are being undertaken in an effort to better define the etiology and pathogenesis of $\mathrm{OA}^{2-4}$. The overall objectives of such studies are to develop novel strategies for prevention and early treatment of OA. Genotype, age, sex, body mass index (BMI) and joint load are the main known risk factors for the development and progression of primary $\mathrm{OA}^{1}$.

Many studies have shown familial aggregation for the occurrence and progression of primary $\mathrm{OA}$ after adjusting for age, sex, and BMI. For example, findings in the Genetics, Arthrosis, and Progression study from the Netherlands showed that familial aggregation of OA is most striking in the hand and hip, and that changes in joint space narrowing are significantly correlated between siblings ${ }^{5}$. The latter studies, however, do not quantify the relative contributions of genetic and environmental factors in family members with OA. The relative contributions of the latter factors have been determined in twin sets after adjustment for the known risk factors. Comparisons of identical and nonidentical twins show that the contribution of genetic factors to radiographic OA of the hand, hip and knee in women is between $39 \%$ and $60 \%{ }^{6}$.

Characterization of the genetic variants responsible for the heritability of OA has evolved through several stages. Many of the early studies focused on genes encoding extracellular matrix macromolecules of articular cartilage ${ }^{7}$. These studies were a natural extension of rapid progress being made in characterizing genetic variants that produced various chondrodysplasias and early-onset OA. For example, mutations of genes encoding the protein chains of type II, IX and XI collagens as well as matrilin 3 and cartilage oligomeric matrix protein were identified in patients with various types of spondyloepiphyseal dysplasia, multiple epiphyseal dysplasia, and pseudoachondroplasia ${ }^{7}$. Most of the mutations of these genes, and of other genes producing chondrodysplasias, resulted in a major reduction in the production of a protein or in abnormal structure and function of a protein. Chondrocyte biology was often seriously impaired because of the retention of unfolded mutant protein within the secretory system ${ }^{7}$. The magnitude of these various metabolic changes indicates that the genetic variants identified in patients with chondrodysplasias and early-onset OA had large gene effect sizes. In contrast, different variants of many of the same genes have been associated with the occurrence and progression of late-onset primary $\mathrm{OA}^{1}$. However, the gene variant effect sizes were small and varied considerably between genders, joint groups, and ethnicity ${ }^{1}$. Because of these generally disappointing results, more recent studies have focused on general genome approaches to identifying genes of potential importance in late-onset primary $\mathrm{OA}^{3,4}$.

Genome-wide linkage scans of families containing multiple members with primary OA revealed linked regions on 12 chromosomes $^{1}$. However, the contribution of each linked region to the OA phenotype was small and variable between countries, genders, and types of OA. For example, a metaanalysis of genome-wide scans from 893 families containing 3000 affected individuals from Iceland, United Kingdom, and United States showed that OA susceptibility genes in these populations were most likely to reside in regions 7q34-7q36.3, 11p12-11q13.4, 6p21.1-6q15, $2 \mathrm{q} 31.1-2 \mathrm{q} 34$, and $15 \mathrm{q} 21.3-15 \mathrm{q} 26.1^{8}$. Genes that may play a role in OA have been identified using association studies of variants of candidate genes selected from the various linked regions, as well as from more recent large scale genome-wide association studies. The associated genes can be grouped into categories such as inflammation (ILI, IL4R, COX2, IL6, IL10, PTGS2, and HLA), cartilage matrix molecules (ASPN, MATN3, COL2A1, COMP, and CILP), Wnt signaling ( $F R Z B$ and $L R P 5)$, bone morphogenetic proteins (BMP2, BMP5, and GDF5), proteases or their inhibitors (ADAM12, TNA, and AACT), and modulators of chondrocytes, osteocytes or osteoclasts (ESRl, VDRl, CALMI, LRCHI and $O P G)^{1}$.

The association of genes involved in inflammation with primary $\mathrm{OA}$ is consistent with the observation that low-grade synovitis is frequent in symptomatic $\mathrm{OA}^{9,10}$. Synovitis also appears to be important in the progression of

See Association between IL1 gene cluster polymorphisms and bilateral DIP OA, page 1977 
OA. For example, the progession of knee OA was greater in patients with synovitis at baseline than in patients without synovitis ${ }^{11}$. The synovitis in OA appears to be driven by cytokines, such as interleukin-1 (IL-1), although the synovial levels of proinflammatory cytokines are lower than in rheumatoid arthritis ${ }^{10}$.

Single locus polymorphisms and extended haplotypes within the ILI gene cluster have been variably associated with hip, knee, and hand $\mathrm{OA}^{1}$. The reasons for the discordant results are unclear but may include differences in IL1 genotype distributions and differences in environmental modulation of the ILI cluster effects on the risk of OA. The article by Solovieva and colleagues in this issue of The Journal provides evidence that joint load may be an important modulator of the effects of the ILI gene cluster on the risk of $\mathrm{OA}^{12}$. In previous studies, they showed that stereotyped repetitive tasks for prolonged periods of time increased the risk of $\mathrm{OA}$ in joints of the thumb, index, and middle fingers among Finnish dentists ${ }^{13}$. In another Finnish study, evidence of genetic linkage was found between distal interphalangeal (DIP) OA of the hand and chromosomal region 2q12-q14, which harbors the ILI gene cluster ${ }^{14}$. Consequently, Solovieva and colleagues evaluated whether the association of DIP OA with ILI gene cluster polymorphisms varies with differential use of the hands. The study groups included Finnish women, between 45 and 63 years of age, who were either dentists with high hand loads or teachers with low hand loads. They found that the minor alleles of $2 I L 1 \beta$ polymorphisms and $2 I L 1 \beta-I L I R N$ extended haplotypes were associated with increased risk of bilateral DIP $\mathrm{OA}$ of the hands in middle-aged and well educated Finnish women. This aspect of the study confirmed previously published findings of a significant association between ILI gene cluster variants and DIP OA in Finnish women ${ }^{14}$. The risk haplotype identified by Solovieva and colleagues includes alleles that have been shown by others to increase the production of IL-1ß, a proinflammatory cytokine, and to decrease the production of IL-1Ra, an antiinflammatory cytokine ${ }^{15}$. Solovieva and colleagues also observed stronger associations between the ILI gene cluster polymorphisms and hand OA in the dentists than in the teachers. This aspect of their study provided support for their proposal that IL-1, and particularly IL-1ß, may be a key mediator in hand OA associated with joint overload.

The results presented by Solovieva and colleagues indicate the need to include joint loading with other environmental factors in future studies of the genetic and environmental aspects of OA. While the other environmental risk factors — age, gender and BMI - are easily recorded, joint loading is likely to be difficult to quantify in patients. Further work will be needed to develop standardized protocols for recording the type and duration of loading of various joints that occur during various occupational, recreational, and other activities.

\author{
WILLIAM COLE, MD, \\ Chief of Pediatric Surgery, \\ Division of Orthopaedic Surgery, \\ University of Alberta, \\ 2C3.65 Walter Mackenzie Health Sciences Centre, \\ 8440112 Street, \\ Edmonton, Alberta T6G 2B7, Canada
}

Address correspondence to Prof. Cole; E-mail: wcole@ualberta.ca

\section{REFERENCES}

1. Valdes AM, Spector TD. The contribution of genes to osteoarthritis. Med Clin North Am 2009;93:45-66.

2. Rodriguez-Lopez J, Pombo-Suarez M, Loughlin J, et al., Association of a nsSNP in ADAMTS14 to some osteoarthritis phenotypes. Osteoarthritis Cartilage 2009;17:321-7.

3. Ryder JJ, Garrison K, Song F, et al., Genetic associations in peripheral joint osteoarthritis and spinal degenerative disease: a systematic review. Ann Rheum Dis 2008;67:584-91.

4. Valdes AM, Loughlin J, Timms KM, Tsezou A, Blanco FJ, Meulenbelt I, et al. Genome-wide association scan identifies a prostaglandin-endoperoxide synthase 2 variant involved in risk of knee osteoarthritis. Am J Hum Genet 2008;82:1231-40.

5. Riyazi N, Meulenbelt I, Kroon HM, Hellio le Graverand MP, Rosendaal FR, Breedveld FC, et al. Evidence for familial aggregation of hand, hip, and spine but not knee osteoarthritis in siblings with multiple joint involvement: the GARP study. Ann Rheum Dis 2005;64:438-43.

6. MacGregor AJ, Antoniades L, Matson M, Andrew T, Spector TD. The genetic contribution to radiographic hip osteoarthritis in women: results of a classic twin study. Arthritis Rheum 2000;43:2410-6.

7. Kannu P, Bateman JF, Belluoccio D, Fosang AJ, Savarirayan R. Employing molecular genetics of chondrodysplasias to inform the study of osteoarthritis. Arthritis Rheum 2009;60:325-34.

8. Lee YH, Rho YH, Choi SJ, Ji JD, Song GG. Osteoarthritis susceptibility loci defined by genome scan meta-analysis. Rheumatol Int 2006;26:959-63.

9. Benito MJ, Veale DJ, FitzGerald O, van den Berg WB, Bresnihan B. Synovial tissue inflammation in early and late osteoarthritis. Ann Rheum Dis 2005;64:1263-7.

10. Farahat MN, Yanni G, Poston R, Panayi GS. Cytokine expression in synovial membranes of patients with rheumatoid arthritis and osteoarthritis. Ann Rheum Dis 1993;52:870-5.

11. Ayral X, Pickering EH, Woodworth TG, Mackillop N, Dougados M. Synovitis: a potential predictive factor of structural progression of medial tibiofemoral knee osteoarthritis — results of a 1 year longitudinal arthroscopic study in 422 patients. Osteoarthritis Cartilage 2005;13:361-7.

12. Solovieva S, Kämäräinen O-P, Hirvonen A, Hämäläinen S, Laitala $\mathrm{M}$, Vehmas T, et al. Association between $I L I$ gene cluster polymorphisms and bilateral distal interphalangeal osteoarthritis. J Rheumatol 2009;36:1977-86.

13. Solovieva S, Vehmas T, Riihimaki H, Takala EP, Murtomaa H, Luoma K, et al. Finger osteoarthritis and differences in dental work tasks. J Dent Res 2006;85:344-8.

14. Leppavuori J, Kujala U, Kinnunen J, Kaprio J, Nissilä M, Heliövaara M, et al. Genome scan for predisposing loci for distal interphalangeal joint osteoarthritis: evidence for a locus on 2q. Am J Hum Genet 1999;65:1060-7.

15. Moos V, Rudwaleit M, Herzog V, Höhlig K, Sieper J, Müller B, et al. Association of genotypes affecting the expression of interleukin-1beta or interleukin-1 receptor antagonist with osteoarthritis. Arthritis Rheum 2000;43:2417-22.

J Rheumatol 2009;36:1864-5; doi:10.3899/jrheum.090554 Personal non-commercial use only. The Journal of Rheumatology Copyright @ 2009 . All rights reserved. 